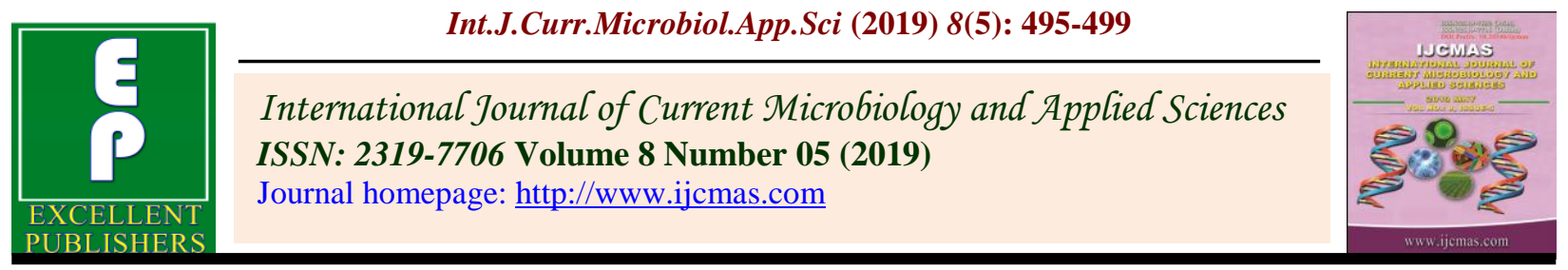

\title{
Standardization, Stability Study and Chemical Properties of Apricot Jam Prepared in Cold Arid Region of Ladakh
}

\author{
Towseef A. Wani ${ }^{*}$, Quraazah A. Amin², S. Fauzia ${ }^{2}$, N. Dorjey ${ }^{1}$, B.A. Zargar1, \\ Phuntsog Tundup ${ }^{1}$, Kunzanglamo ${ }^{1}$, N. Deldan ${ }^{1}$, R. Safal ${ }^{1}$ and M.A. Beigh ${ }^{2}$ \\ ${ }^{1}$ Krishi Vigyan Kendra Leh, SKUAST-K, J\&K, India \\ ${ }^{2}$ Division of Food Science and Technology, SKUAST-K, J\&K, India \\ *Corresponding author
}

\begin{tabular}{|l|}
\hline K e y w o r d s \\
Apricot, Pectin, \\
Jam, TSS, Sugars \\
\hline Article Info \\
\hline $\begin{array}{l}\text { Accepted: } \\
\text { 07 April } 2019 \\
\text { Available Online: } \\
\text { 10 May 2019 }\end{array}$ \\
\hline
\end{tabular}

\section{A B S T R A C T}

This research was conducted to prepare apricot jam from the pulp of fresh mature apricots by using artificial sweeteners .Apricots were washed with clean water to remove dust particles. After sorting and pitting, apricots were cut into two halves and dipped in $0.1 \%$ citric acid solution to avoid browning. The pulp of apricots was extracted by using plumper. Apricot pulp was heated to get the desired consistency. Low heating was continued and brix were noted after every 20 minutes. Pectin with small amount of nonnutritive sweeteners were dissolved separately and added to the mixture. Apricot jam can be used for the lean period, as Ladakh remains cutoff from the whole world at least for six months. The possibility of converting fresh apricots into jam has been investigated in this study that showed a great promise in its manufacture. The samples were studied for their chemical characteristics up to 90 days of storage. The parameters (i.e.), Titrable acidity, $\mathrm{pH}$, reducing sugar, Total sugar, TSS were determined in apricot jam. Physico-Chemically the mean values of the results were $1.01,3.52,36.4,53.64$ and 68.00 respectively.

\section{Introduction}

Apricot (Prunus armeniaca L.) is the specie of Prunus, which can be classified with the Prunoidae subfamily Rosacea (Haydar et al., 2007), is the most important fruit crop of Ladakh. Its production is mostly confined to the lower belt (double cropped area) of Ladakh, where the climate is milder. The lower belt includes areas from Saspol to Batalik, Nubra valley and larger parts of Kargil. The crop is intimately associated with the culture and traditions of the region because it is one of the major sources of livelihood. Almost every part of the fruit is used by the local inhabitants; ripe apricot is an excellent dessert fruit and is used for table purposes having direct influence on the upliftment of the farming community of the region.

Jam is the product that contains fruit pulp from whole fruit or more kinds of fruit boiled with sufficient quantity of sugars at low $\mathrm{pH}$ (2.5-3.2) to produce a tissue with firm and gel like consistency with or without addition of 
water (Codex Ailamentarus, 2009). Pectin and acids are added to obtain a good quality jam with total solids and fruit accounting not less than $65 \%$ and $45 \%$ respectively. Jams are good carriers of fruit related components to humans finding their way during early hours on ones breakfast table. This fruit is pleasant and having a charming aroma that's why it is consumed worldwide (Gutierrez et al., 2007). Nutritionally, apricot is a rich source of sugars, fibers, minerals, and vitamins (thiamine, riboflavin, niacin and pantothenic acid) (Sartaj et al., 2011). It also contains considerable amounts of carotenoids (in the form of b-carotene), and bioactive phytochemicals like chlorogenic, caffeic, pcoumaric and ferulic acids (Dragovic et al., 2007).

The phenolics present in apricots mainly include hydroxycinnamic and hydroxybenzoic acids impart it with antioxidant properties (Hussain et al., 2013). The study by Vardi et al., (2013) showed the protective role of apricots against the renal failure and apoptosis. The annual production of apricots in India is 18,000 tones limited to arid regions of Ladakh, Kashmir and Himachal Pradesh, contributing a negligible percentage of $0.45 \%$ to the world's production (Aina and Adesina, 1991).

\section{Materials and Methods}

Fresh mature apricots were purchased from Leh region of Ladakh and were transported in wooden crates to the, Krishi Vigyan Kendra Leh where the work was carried out.

\section{Pre blanching operation}

Apricots were washed with clean water to remove dust and extraneous material. Then after pitting apricots were cut into two haves and were submerged in $1 \%$ citric acid solution.

\section{Blanching}

Pitted apricot halves were blanched in citric acid solution $(0.1 \%)$ for two minutes to avoid possible enzymatic reactions.

\section{Pulp extraction}

Fruit pulp was extracted with the help of grinder/juicer by adding the apricot pieces in pulp extracting machine.

\section{Preparation of jam}

Different ratios of sweeteners non caloric were taken and used for jam preparation according to the formula and procedure of Awan and Rehman (1999). The jam samples were cooked in the open steel container. The fruit pulp were taken in an open container and heated. At the same time commercial grade pectin with small amount of non caloric sweeteners were dissolved separately and added to the mixture in container. Preservatives and color was added at the end of cooking.

\section{Physico-chemical analysis}

The prepared product was analyzed for Total Soluble Solids, Acidity, pH, Reducing sugars and Total sugars.

\section{Titrable acidity and pH value}

The acidity as determined by titration methods (Rangana, 1986) is a measure of stability and shelf life of jam. The organic acids present in fruits and those added during making the jam manufacture contribute to the acidity and thus decrease the $\mathrm{pH}$. The $\mathrm{pH}$ was measured by the standard procedures of AOAC (AOAC, 2005). The sample prepared for the $\mathrm{pH}$ determination involved weighing of $25 \mathrm{gm}$ of the sample and dissolving it in $200 \mathrm{ml}$ of distilled water followed by boiling 
on a water bath for 1 hour. The solution was cooled and diluted to $250 \mathrm{ml}$ with distilled water, filtered and used for analysis. The $\mathrm{pH}$ was determined by using a digital $\mathrm{pH}$ meter.

$\%$ Titrable Acidity $=$
The titrable acidity was expressed as \% citric acid and calculated by the following formula:

Titre $\mathrm{x}$ normality of alkali x vol. made x eq. weight of major acid x 100

Volume of sample taken for estimation $\mathrm{x}$ Wt. of sample taken $\mathrm{x} 1000$

\section{Reducing sugars and total sugars}

The reducing sugars were determined by Lane and Enyon method (Rangana, 1986) which determines the reducing sugars, expressed as invert sugar that reduces the copper in Fehling's solution to red, insoluble cuprous oxide. The procedure involves blending 50 gm of sample with $400 \mathrm{ml}$ of water and neutralizing it with $1 \mathrm{~N}$ sodium hydroxide using phenolphthalein indicator, followed by gently boiling for about an hour and maintaining its water level during the boiling. The cooled solution is filtered and put into $500 \mathrm{ml}$ volumetric flask marking up the volume and taking out $100 \mathrm{ml}$ aliquot added with $200 \mathrm{ml}$ water and $2 \mathrm{ml}$ neutral lead acetate solution, the excess of the later is precipitated with potassium oxalate solution.

The sugar solution was titrated with $10 \mathrm{ml}$ of mixed Fehling solution and $50 \mathrm{ml}$ water in a $250 \mathrm{ml}$ flask to reduce almost completely the Fehling's solution. The flask was heated and boiled for 15 seconds with persistence of blue color indicating unreduced Fehling solution and adding few more $\mathrm{ml}$ of sugar solution until whole of the Fehling's solution gets reduced. The presence of faintest perceptible blue color is the time for adding few drops of methylene blue followed by adding sugar solution until the indicator is completely decolorized. The readings were recorded and then employed used in the calculation of $\%$ reducing sugars as:
$\%$ Reducing Sugars $=$

$\underline{\text { mg of invert sugar x dilution } \mathrm{x} 100}$

Titre $\mathrm{x}$ volume of sample $\mathrm{x} 100$

$\%$ Total sugars are also calculated from the above equation making use of titre value obtained in the determination of total sugars.

\section{Total soluble solids}

Total soluble solids were determined by a refractometer at room temperature and applying the temperature correction to correct the reading. The observed TSS as ${ }^{\circ} \mathrm{B}$ determines percentage of the TSS in the jam.

\section{Results and Discussion}

The analyzed tritable acidity (\%), pH, reducing sugars (\%), total sugars (\%) and TSS $\left(\mathrm{B}^{\mathrm{o}}\right)$, of jam just after preparation and at an interval of $0,30,60$ and 90 days of storage are presented in Table 1. The parameters showed a notable change during the storage period.

\section{Acidity and pH}

The results pertaining to the titrable acidity (Table 1) showed its increase during storage from $1.01 \%$ to $1.233 \%$. The results correlated with Hussain and Shakir (2010), for mixed jam (apple and apricot) with different formulations (Gowda et al., 2005). To obtain optimum gel conditions of jam the $\mathrm{pH}$ is an 
important factor and its estimation during storage provides us the information whether it was maintained or not during the entire study for effective preservation. The values of $\mathrm{pH}$ (Table 1) reveal its decrease due to the formation of acidic compounds. The results were similar with Ehsan et al., (2003).

\section{Total soluble solids $\left({ }^{0} \mathrm{Brix}\right)$}

Total soluble solids showed a gradual increase during storage period from 68 to 74 ${ }^{\mathrm{o}} \mathrm{B}$. The solubilization of the jam constituents may be the reason of its increase. Similar results were reported by Hussain and Shakir (2010).

\section{Total sugars and reducing sugars (\%)}

There is a gradual increase in the reducing sugar content of the jam during the storage from 36.4 to $45.3 \%$ (Table 1). The same results are shown by Vidhya and Narain (2011). The inversion of sucrose into reducing sugar (glucose and fructose) due to acid and high temperature during storage results in its increase. The increase can also be due to prolonged storage and hydrolysis of sugars with increase in acidity and decrease in $\mathrm{pH}$.. The increase in total sugars from 53.64 to 57.02 resulted due to formation of sugars from insoluble carbohydrates and starch. The same increase in sugar is reported by Pota et al., (1987) due to formation of sugars from other complex carbohydrates. The Statistical analysis revealed that the effect of storage on total and reducing sugars of the jam is significant $(\mathrm{p} \leq 0.05)$.

Table.1 Storage effect on the chemical constituents of apricot jam

\begin{tabular}{|l|l|l|l|l|l|}
\hline Parameters & 0 day & $\mathbf{3 0}$ days & 60 days & 90 days & Mean \\
\hline Titrable acidity (\%) & 1.01 & 1.12 & 1.19 & 1.23 & 1.13 \\
\hline pH & 3.52 & 3.43 & 3.32 & 3.24 & 3.37 \\
\hline Reducing sugars (\%) & 36.4 & 40.1 & 43.2 & 45.3 & 41.25 \\
\hline Total sugars (\%) & 53.64 & 55.51 & 56.15 & 57.02 & 55.58 \\
\hline TSS $(\mathbf{0} \mathbf{B})$ & 68.00 & 70.00 & 72.00 & 74.00 & 71.00 \\
\hline
\end{tabular}

In conclusion, the apricot-date as prepared successfully remained acceptable for 90 days after storage (DAS). There was a gradual increase in all the observed parameters due to hydrolysis or conversion of one compound into other and maintaining a low $\mathrm{pH}$ throughout the storage necessary for the preservation process.

\section{References}

Aina, J.O. and Adesina, A.A. (1991). Quality attributes of jams from low usage tropical fruits. Food Chemistry, 40: 345-351.

Awan, J., Salim UR (1999) Food Preservation manual Uni-Tech. Comp. Faisalabad

Dragovic-Uzelac, V., Levaj B, Mrkic V, Bursac D, Marija Boras M. 2007. The content of polyphenols and carotenoids in three apricot cultivars depending on stage of maturity and geographical region. Food Chemistry 102, 966-975.

Ehsan, EB., Naeem ZP, Javed A and Nazir A (2003). Development, standardization 
and storage studies on grape fruit apple marmalade. Pakistan Journal of Food Science, 13: 11-15

Gowda, A., Nallakurumban SM and Kalaiselvan (2005). Studies on storage stability of guava fruit bar indifferent packaging materials. Beverage and FoodWorld, 32: 80-81.

Gutierrez-Martinez, P., Schorr-Galindo, S, Ragazzo-Sanchez, J.A. 2007. Discrimination of eight arieties of apricot (Prunus armeniaca L) by electronic nose, LLE and SPME using GC-MS and multivariate analysis. Sensors and Actuators B 125, 415421.

Haydar, H., Ibrahim, G., Mehmet, O.M., Bayram M. 2007. Post-harvest chemical and physical mechanical properties of some apricot varieties cultivated in Turkey. Journal of Food Engineering 79, 364-373.

Hussain, I., and Shakir, I. (2010). Chemical and organolepticcharacteristics of jam prepared from indigenous varieties of apricot and apple. World Journal ofDiary and Food Sciences, 5: 73-78.

Hussain, PR., Chatterjee S, Variyar PS, Sharma A, Dar MA and Wani AM (2013). Bioactive compounds and antioxidant activity of gamma irradiated sun dried apricots (Prunus armeniaca L.). Journal of Food Composition and Analysis, 30: 59-66.

Pota, SO., Ketsa, S. and Thongtham, M.L. (1987). Effect ofpackaging material and temperature on quality andstorage life of pomegranate fruits. Journal ofNatural Science, 23: 328-333

Rangana, S., (1986). Handbook of analysis and qualitycontrol for fruit and vegetable products. McGraw- Hill, New Dehli.

Sarta,j A., Tariq M, Kashif Sarfraz A. 2011. Physico-chemical characteristics of apricot (Prunus armeniaca L.) grown in northern areas of Pakistan. Scientia Horticulturae 130, 386-392.

Vidhya, R., and Narain, A. (2011). Development of preserved products using under exploited fruits, Wood Apple. American Journal of Food Technology, 6: 279-288.

Vardi, N., Parlakpinar H, Ates B, Cetin A and Otlu A (2013). The protective effects of Prunus armeniaca L (apricot) against methotrexate-induced oxidative damage and apoptosis in rat kidney. Journal of Physiology and Biochemistry, 69: 371-381.

\section{How to cite this article:}

Towseef A. Wani, Quraazah A. Amin, S. Fauzia, N. Dorjey, B.A. Zargar, Phuntsog Tundup, Kunzanglamo, N. Deldan, R. Safal and Beigh, M.A. 2019. Standardization, Stability Study and Chemical Properties of Apricot Jam Prepared in Cold Arid Region of Ladakh. Int.J.Curr.Microbiol.App.Sci. 8(05): 495-499. doi: https://doi.org/10.20546/ijcmas.2019.805.058 